\title{
Application of variable equivalent amplitude for determination of fatigue life of elements subjected to block loading
}

\author{
Justyna Obra1 ${ }^{1}$, Marta Kurek $^{1}$, Tadeusz Lagoda $^{1 *}$, and Karolina Głowacka ${ }^{1}$ \\ ${ }^{1}$ Faculty of Mechanical Engineering, Opole University of Technology, 45-407 Opole, Mikołajczyka \\ 5, Poland
}

\begin{abstract}
This paper contains a proposition of a new method of determining the fatigue life of elements subjected to non-stationary loads. The model was based on the determination of the time-variable equivalent weighted amplitude. This amplitude is derived on a continuous basis as the arithmetic mean of nth root of the amplitudes that occur up to a given time. The analysis of the proposed model was carried out on the basis of selected literature insights based on specimens made of P91 and P92 steels. The experimental tests were performed under block loading with a zero mean value in the conditions of tension-compression with a small number of cycles.
\end{abstract}

\section{Introduction}

For many years, a hypothesis of fatigue damage accumulation has been sought, which could be used for fatigue damage accumulation in the case of other cases than loads with constant amplitude. The first of the proposals was given by Palmgren [1]. This first study offered an account of the phenomenon of damage in ball bearing coupled with a description of the damage accumulation model. The hypothesis was later refined and disseminated by Miner [2], but it cannot be applied for all load conditions. Many hypotheses concerning the damage accumulation of have been developed, e.g. the Haibach [3], Serensen-Kogayen [4], Zenner [5] hypotheses. These hypotheses describe the phenomenon of fatigue damage accumulation relatively well with regard to stationary histories. The case is completely different for the case of non-stationary loads. Such loads can be conveniently described in terms of block loading. One of them is the High - Low (H-L) and Low - High (H-L) type block two-level program. On the basis of such loads, another hypothesis named after Marko-Starkey [6] was formulated, in which a distinction is made between loading blocks, number of cycles and the material constant characteristic for a given material. On the other hand, the monograph by Szala [7] contains a discussion including the description of the fatigue damage accumulation hypothesis in terms of the stress, energy and strain model, and offers a summary of the scientific achievements in the area of research concerned with fatigue damage accumulation. All subsequent hypotheses of the accumulation of fatigue damage have been developed on the basis of the Palmgren-Miner model, and thus, form its derivatives. In recent years, a

\footnotetext{
*Corresponding author: t.lagoda@po.edu.pl
} 
variety of hypotheses have been proposed to take into account the memory of a material which forms an aggregate of the history of loading states. This solution was taken from the field of psychology and the Ebbinghaus model [8]. In [9-12] models can be found in which the memory of the material is taken into account. Hence, two models have been developed: - exponential model

$$
D^{\prime}=\sum_{i=1}^{j} \frac{N_{f}}{d} \frac{e^{\frac{-N}{d}}}{\left(1-e^{\frac{N_{f}}{d}}\right)} \frac{1}{N_{f i}}
$$

where: $\mathrm{d}$ - material constant, $\mathrm{N}$ - current number of cycles, $\mathrm{N}_{\mathrm{r}}$ - cumulative number of cycles to failure, $\mathrm{N}_{\mathrm{fi}}$ - total number of cycles to failure corresponding to a given load amplitude;

- power law model

$$
D^{\prime}=\sum_{i=1}^{j}\left[\frac{1-\varphi}{2^{1-\varphi}-1}\left(1+\frac{N}{N_{f}}\right)^{-\varphi}\right] \frac{1}{N_{f i}}
$$

where: $\varphi$-material constant, $\mathrm{N}$ - current number of cycles, $\mathrm{N}_{\mathrm{f}}-$ cumulative number of cycles to failure, $\mathrm{N}_{\mathrm{fi}}$ - total number of cycles to failure corresponding to a given load amplitude;

Subsequently, it has been demonstrated that both models describe the results of experimental studies relatively well. Unfortunately, these models cannot be utilized for fatigue life assessment without gaining prior information regarding this fatigue life, as the calculations require the total number of cycles to failure $\left(\mathrm{N}_{\mathrm{f}}\right)$.

For many years, a model has been sought for the purpose of representing the results of research that could be applied with regard to other cases other loads than with constant amplitude. The first such proposition is the Gassner model [13], which adopted the characteristic maximum amplitude as the amplitude. However, under such assumption, one cannot compare histories with different statistical characteristics, including studies with a constant amplitude histories. Therefore, many authors propose to use different models for determining the equivalent amplitude $[1,2,13]$. A more comprehensive overview of the various models for the presentation of variable amplitudes can be found in the study reported in [14]. This paper covers eight methods of presenting the results of fatigue tests for loads with variable and constant amplitudes. It appears that some methods can be applied to investigate cases of variable and constant-amplitude loads, and some cannot. One promising method is the method applying the root mean $n$ of the amplitude, where $n$ is selected experimentally. This model is characterized by the aggregation of all cycles that are greater than the knee point $\sigma_{\mathrm{ak}}$ of the root mean $n$. In one approach it is assumed that $n=m$, where $\mathrm{m}$ is the $\boldsymbol{m}$-power exponent of fatigue diagram in the Basquin model.

$$
\sigma_{a n}=\left[\frac{\Sigma_{i} \sigma_{a i}^{n}}{N_{b}}\right]^{\frac{1}{n}} d l a \sigma_{a i}>a \cdot \sigma_{a k}
$$

where $N_{b}$ is the cumulative number of cycles.

This model can also be described in the case of strains under the assumption of a new factor $n=c$ ", where c" forms an exponent of the strain characteristic and it will form the subject the discussion in the further sections of this work. Such an analysis applies a section of the strain characteristic in double logarithmic coordinates

$$
\varepsilon_{a n}=\left[\frac{\sum_{i} \varepsilon_{a i}^{n}}{N_{b}}\right]^{\frac{1}{n}} d l a \varepsilon_{a i}>a \cdot \varepsilon_{a k}
$$


Therefore, it seems that it is feasible to propose a model that will form an aggregate with the memory of the load history in the form of a weighted amplitude from the time history up to a given moment in time and on this basis damage can be accumulated on an ongoing basis. Thus, the aim of this study is to develop such a model and its verification on the basis of on fatigue tests available in the literature, performed on specimens made of P91 and P92 steel in the range of a small number of cycles.

\section{Damage accumulation model applying weighted amplitude}

The standard stress characteristic can be expressed in the form of the Basquin characteristic as

where:

$$
\sigma_{a}=\sigma_{f}^{\prime}\left(2 N_{f}\right)^{b}
$$

$\sigma_{a}-$ strain amplitude

$\sigma_{f}^{\prime}$ - coefficient of plastic fatigue strain,

$2 N_{f}$ - number of half - cycles,

$\mathrm{b}$ - fatigue life exponent.

At the same time, strain characteristic can be expressed as

$$
\varepsilon_{a}=\frac{\sigma_{f}^{\prime}}{E}\left(2 N_{f}\right)^{b}+\varepsilon_{f}^{\prime}\left(2 N_{f}\right)^{c}
$$

where:

$\varepsilon_{a}$ - amplitude of total strain,

$E-$ Young's modulus,

$\varepsilon_{f}^{\prime}$-fatigue life factor,

$\mathrm{c}-$ coefficient of plastic fatigue strain.

We can note that within small ranges of life, the waveform (6) can be expressed as a straight line in double logarithmic coordinates in the form

where:

$$
\varepsilon_{a}=\varepsilon^{\prime \prime}\left(2 N_{f}\right)^{c^{\prime \prime}}
$$

$\varepsilon^{\prime \prime}$ - fatigue life factor in the simplified strain characteristic,

$c "-$ coefficient of plastic fatigue strain in the simplified strain characteristic.

In accordance with the linear aggregation of damage, the total damage in the first block with the number of cycles equal to $\mathrm{n}_{1}$ and level of strain amplitude equal to $\varepsilon_{\mathrm{a} 1}$ can be derived from the relation

$$
S_{1}\left(n_{1}\right)=\frac{n_{1}}{N_{f 1}}=2 n_{1}\left(\frac{\varepsilon_{f}^{\prime \prime}}{\varepsilon_{1 a}}\right)^{1 / c^{\prime \prime}}
$$

In accordance with the Palmgren-Miner hypothesis, we can derive the following for the second loading block 


$$
S_{2}\left(n_{2}\right)=\frac{n_{1}}{N_{f 2}}=2 n_{2}\left(\frac{\varepsilon^{\prime \prime} f}{\varepsilon_{2 a}}\right)^{1 / c^{\prime \prime}}
$$

Finally, the degree of damage that accounts for the partial damage expressed in (8) and (9) can be written as

$$
\mathrm{D}=S_{1}\left(n_{1}\right)+S_{2}\left(n_{2}\right)=1
$$

The weighted strain amplitude can be established on the basis of formula (4) as

$$
\varepsilon_{a e q i}=\left(\frac{n_{1} \varepsilon_{1 a}^{n}+i \varepsilon_{2 a}^{n}}{n_{1}+i}\right)^{1 / n}
$$

where

$$
n=-\frac{1}{c^{\prime \prime}}
$$

Additionally, a second model can be proposed, in which the arithmetic mean of the current amplitude and the weighted amplitude of $n$-th root (in accordance with formula in 12) with regard to the $i$-th cycle of the second level can be applied to account for damage accumulation

$$
\varepsilon_{\text {aeqi,mean }}=\frac{\varepsilon_{a e q i}+\varepsilon_{2 a}}{2}
$$

In relation with this, the damage degree following $\mathrm{i}$-th cycle takes the form of an expression for the weighted amplitude

$$
S_{1,2 i}=2 n_{1}\left(\frac{\varepsilon_{f}^{\prime \prime}}{\varepsilon_{1 a}}\right)^{1 / c^{\prime \prime}}+\sum_{i=1}^{n_{2, c a l}} 2\left(\frac{\varepsilon_{f}^{\prime \prime}}{\varepsilon_{1 \text { aeqi }}}\right)^{1 / c^{\prime \prime}}
$$

as well as mean amplitude

$$
S_{1,2 i}=2 n_{1}\left(\frac{\varepsilon_{f}^{\prime \prime}}{\varepsilon_{1 a}}\right)^{1 / c^{\prime \prime}}+\sum_{i=1}^{n_{2, c a l}} 2\left(\frac{\varepsilon^{\prime \prime} f}{\varepsilon_{1 \text { aeqi } m \text { mean }}}\right)^{1 / c^{\prime \prime}}
$$

In connection with this, if the damage degree $S_{1,2 i}$ assumes a value at a second level that conforms to the Palmgren-Miner hypothesis at the second level following i-th cycle

$$
S_{1,2 i}=\mathrm{D}=1
$$

the forecasted number of cycles in the second-stage loading block is expressed by the relation

$$
n_{2, c a l}=i
$$

\section{Experimental research}

Junak and Cieśla [15] conducted experimental research with regard to P91 and P92 steels for loading blocks. The chemical composition of these steels is summarized in Table 1. The summary of static and fatigue properties can be found in Tables 2 and 3, respectively. The fatigue life of the steel was determined for the following strain amplitudes: $\varepsilon_{\mathrm{a}}$ equal to 0.3 and $0.6 \%$, simultaneously using two-level loading blocks. When an analysis was carried out 
of the test results for P91 and P92 steels, it turned out that for constant strain amplitudes, the low-cycle fatigue characteristics are similar. The fatigue characteristics (6) assume a virtually linear course in double logarithmic coordinates, similarly to the case of the linear proposal, in accordance with (7) along the waveform represented by the strain amplitudes equal to 0.3 and $0.6 \%$, where the fatigue life range is equal to $(720,3780)$ and $(640,3302)$ cycles, for P91 and P92 steels, respectively. Consequently, we can conclude that for such a range of amplitudes, the assumption of linearity in a dual logarithmic coordinates is fully feasible, since these characteristics practically overlap.

Table 1. Chemical composition of P91 and P92 steels, wt. \%, Fe the rest

\begin{tabular}{|c|c|c|c|c|c|c|c|c|c|}
\hline Steel & $\mathrm{C}$ & $\mathrm{Si}$ & $\mathrm{Mn}$ & $\mathrm{P}$ & $\mathrm{S}$ & $\mathrm{Ni}$ & $\mathrm{Cr}$ & $\mathrm{Mo}$ & $\mathrm{W}$ \\
\hline P91 & 0.10 & 0.36 & 0.42 & 0.017 & 0.004 & 0.13 & 8.75 & 0.96 & - \\
\hline P92 & 0.11 & 0.30 & 0.60 & 0.017 & 0.004 & 0.20 & 9.50 & 0.50 & 1.90 \\
\hline
\end{tabular}

Table 2. Static properties of P91 and P92 steels

\begin{tabular}{|c|c|c|c|c|}
\hline Steel & $\begin{array}{c}\mathrm{R}_{\mathrm{m}} \\
{[\mathrm{MPa}]}\end{array}$ & $\begin{array}{c}\mathrm{R}_{0,2} \\
{[\mathrm{MPa}]}\end{array}$ & $\begin{array}{c}\mathrm{A}_{5} \\
{[\%]}\end{array}$ & $\begin{array}{c}\mathrm{Z} \\
{[\%]}\end{array}$ \\
\hline P91 & 694.4 & 544.6 & 23.8 & 71.4 \\
\hline P92 & 705.7 & 529.7 & 25.4 & 67.5 \\
\hline
\end{tabular}

Table 3. Fatigue properties of P91 and P92 steels

\begin{tabular}{|c|c|c|c|c|c|c|}
\hline Steel & $\sigma_{f}^{\prime} / \mathrm{E}$ & $b$ & $\varepsilon_{f}^{\prime}$ & $c$ & $\varepsilon_{f}$ & $\mathrm{c}{ }^{\prime \prime}$ \\
\hline P91 & 0.065 & -0.028 & 1.02 & -0.74 & 12.54 & -0.418 \\
\hline P92 & 0.063 & -0.028 & 1.01 & -0.64 & 12.30 & -0.422 \\
\hline
\end{tabular}

\section{Model validation}

Tables 4 and 5 contain the test results for the analyzed loading blocks carried out with regard to P91 and P92 steels, respectively. Specimens with numbers 1_1-1_5 and 2_1-2_8 denote $\mathrm{H}-\mathrm{L}$ loads. The others apply to $\mathrm{L}-\mathrm{H}$ loads. In addition, these tables contain a summary of the calculations of the life of the second block in accordance with the Palmgren-Miner model, the weighted amplitude (11) and the arithmetic mean value of the current load amplitude and the weighted amplitude (13).

Figs 1 and 2 contain the presentation of the method applied for determining the equivalent amplitude for $\mathrm{H}-\mathrm{L}$ and $\mathrm{L}-\mathrm{H}$ loads, respectively, derived on the basis of the three analyzed models. From the analysis of these figures, we can see that in the case of the root mean $n$ of amplitude (c"), this amplitude from the initial value equal to the amplitude from block type 1 asymptotically approaches the amplitude from the second block. In the case of using an average value, the amplitude for accumulation in the second block starts from the arithmetic mean of the first and second block until it asymptotically approaches the one given in the second block along with its aggregation. The approximation is much faster than when only the root mean $\mathrm{n}$ of amplitude (c") is applied.

The comparison of the computational life with the experimental ones derived in accordance with these three models is presented in Figs. 3 and 4. Regardless of the use of material, on the basis of the analysis of Figs. 3 and 4 we can see that in the case when H-L type loads 
using the classic Palmgren-Miner hypothesis are applied, fatigue life is overestimated, and in the case of $\mathrm{L}-\mathrm{H}$ loading type, it is underestimated. For the case when the root mean $\mathrm{n}$ of amplitude (c") is applied for fatigue damage accumulation, it is exactly the opposite case. Only the use of the arithmetic mean amplitude of the second block and the weighted amplitude in a given cycle offers satisfactory results of the computational fatigue life of the second block. These results are the closest to the straight line describing the ideal conformity between the computational life and the experimental one.

Table 4. Summary of experimental and computed results for the second loading block for P91 steel

\begin{tabular}{|c|c|c|c|c|c|c|c|}
\hline Specimen & $\varepsilon_{\mathrm{a} 1}$ & $\mathrm{n}_{1}$ & $\varepsilon_{\mathrm{a} 2}$ & $\mathrm{n}_{2, \exp }$ & $\mathrm{n}_{2, \mathrm{PM}}(10)$ & $\mathrm{n}_{2, \text { waz }}(11)$ & $\mathrm{n}_{2, \text { mean }}(14)$ \\
\hline $1 \_1$ & 0.6 & 72 & 0.3 & 3137 & 3402 & 2331 & 2886 \\
\hline $1 \_2$ & 0.6 & 130 & 0.3 & 2835 & 3100 & 1654 & 2371 \\
\hline $1 \_3$ & 0.6 & 346 & 0.3 & 1210 & 2570 & 557 & 1089 \\
\hline $1 \_4$ & 0.6 & 432 & 0.3 & 945 & 1512 & 373 & 754 \\
\hline $1 \_5$ & 0.6 & 518 & 0.3 & 567 & 1058 & 237 & 482 \\
\hline $1 \_6$ & 0.3 & 1058 & 0.6 & 684 & 518 & 1149 & 793 \\
\hline $1 \_7$ & 0.3 & 1399 & 0.6 & 662 & 454 & 1120 & 729 \\
\hline $1 \_8$ & 0.3 & 2041 & 0.6 & 605 & 331 & 979 & 573 \\
\hline $1 \_9$ & 0.3 & 2495 & 0.6 & 540 & 245 & 817 & 442 \\
\hline $1 \_10$ & 0.3 & 3062 & 0.6 & 338 & 137 & 539 & 259 \\
\hline
\end{tabular}

Table 5. Summary of experimental and computed results for the second loading block for P92 steel

\begin{tabular}{|c|c|c|c|c|c|c|c|}
\hline Specimen & $\varepsilon_{\mathrm{a} 1}$ & $\mathrm{n}_{1}$ & $\varepsilon_{\mathrm{a} 2}$ & $\mathrm{n}_{2, \exp }$ & $\mathrm{n}_{2, \text { PM }}(10)$ & $\mathrm{n}_{2, \text { waż }}(11)$ & $\mathrm{n}_{2, \text { mean }}(14)$ \\
\hline $2 \_1$ & 0.6 & 64 & 0.3 & 2808 & 2974 & 2056 & 2538 \\
\hline $2 \_2$ & 0.6 & 96 & 0.3 & 2313 & 2808 & 1661 & 2248 \\
\hline $2 \_3$ & 0.6 & 154 & 0.3 & 1222 & 2511 & 1153 & 1804 \\
\hline $2 \_4$ & 0.6 & 205 & 0.3 & 1553 & 2247 & 857 & 1480 \\
\hline $2 \_5$ & 0.6 & 301 & 0.3 & 1057 & 1751 & 515 & 993 \\
\hline $2 \_6$ & 0.6 & 403 & 0.3 & 793 & 1222 & 302 & 606 \\
\hline $2 \_7$ & 0.6 & 448 & 0.3 & 463 & 991 & 231 & 466 \\
\hline $2 \_8$ & 0.6 & 544 & 0.3 & 330 & 496 & 107 & 213 \\
\hline $2 \_9$ & 0.3 & 727 & 0.6 & 588 & 499 & 1014 & 733 \\
\hline $2 \_10$ & 0.3 & 1487 & 0.6 & 499 & 352 & 944 & 588 \\
\hline $2 \_11$ & 0.3 & 1949 & 0.6 & 403 & 390 & 814 & 464 \\
\hline $2 \_12$ & 0.3 & 2313 & 0.6 & 301 & 192 & 668 & 354 \\
\hline $2 \_13$ & 0.3 & 2808 & 0.6 & 147 & 96 & 402 & 188 \\
\hline
\end{tabular}

On the basis of the data contained in Tables 5 and 6, an analysis of scatter bands was performed by application of the relation in accordance with the proposal presented in [16]

$$
E_{R M S}=\sqrt{\frac{\sum \log ^{2} \frac{n_{2, \text { exp }}}{n_{2, \text { cal }}}}{n}},
$$

where $\mathrm{n}$ is the number of specimens.

Finally, the mean scatter can be determined on the basis of the relation:

$$
T_{R M S}=10^{E_{R M S}} .
$$


A summary of the results of calculations of the scatters determined in this way can be found in Table 6 on the basis of the relation in (19). From the analysis of the calculations contained in this table, we can see that the TRMS scatters are definitely the smallest when using damage accumulation using the amplitude as the arithmetic mean of the current amplitude and the current root mean $\mathrm{n}$ of amplitude (c")

Table 6.Summary of scatters between calculated and experimental lives

\begin{tabular}{|c|c|c|c|c|}
\hline Material & loading & $T_{R M S, P M}(10)$ & $T_{R M S, \text { waż }}(11)$ & $T_{R M S, \text { mean }}(14)$ \\
\hline P91 & H-L & 1.629 & 2.058 & 1.173 \\
\hline P91 & L-H & 1.889 & 1.621 & 1.186 \\
\hline P92 & H-L & 1.624 & 1.986 & 1.262 \\
\hline P92 & L-H & 1.386 & 2.126 & 1.210 \\
\hline
\end{tabular}

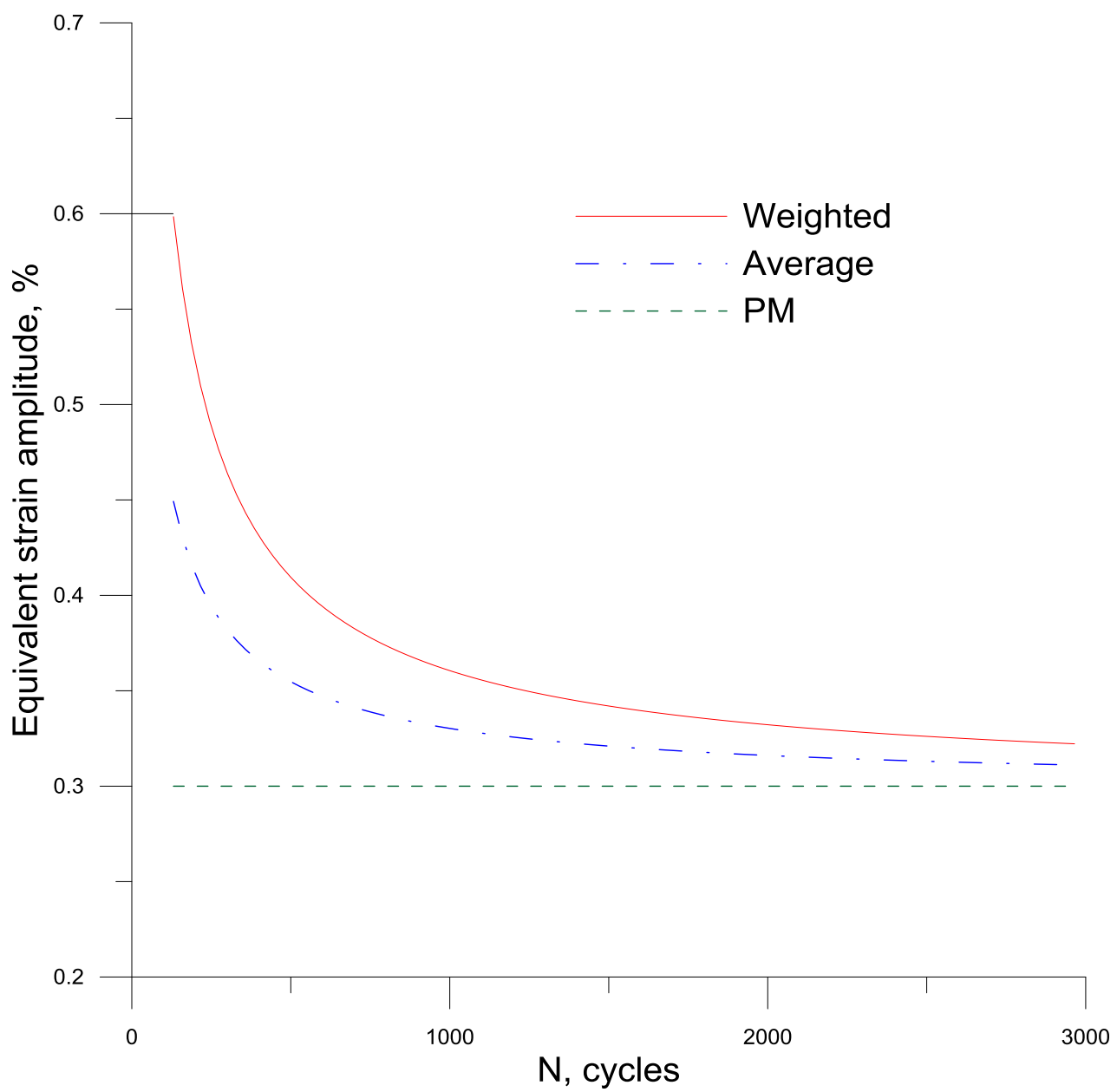

Fig. 1. Equivalent strain amplitude for H-L level of P91 steel in the function of the current number of cycles based on specimen 1_2 


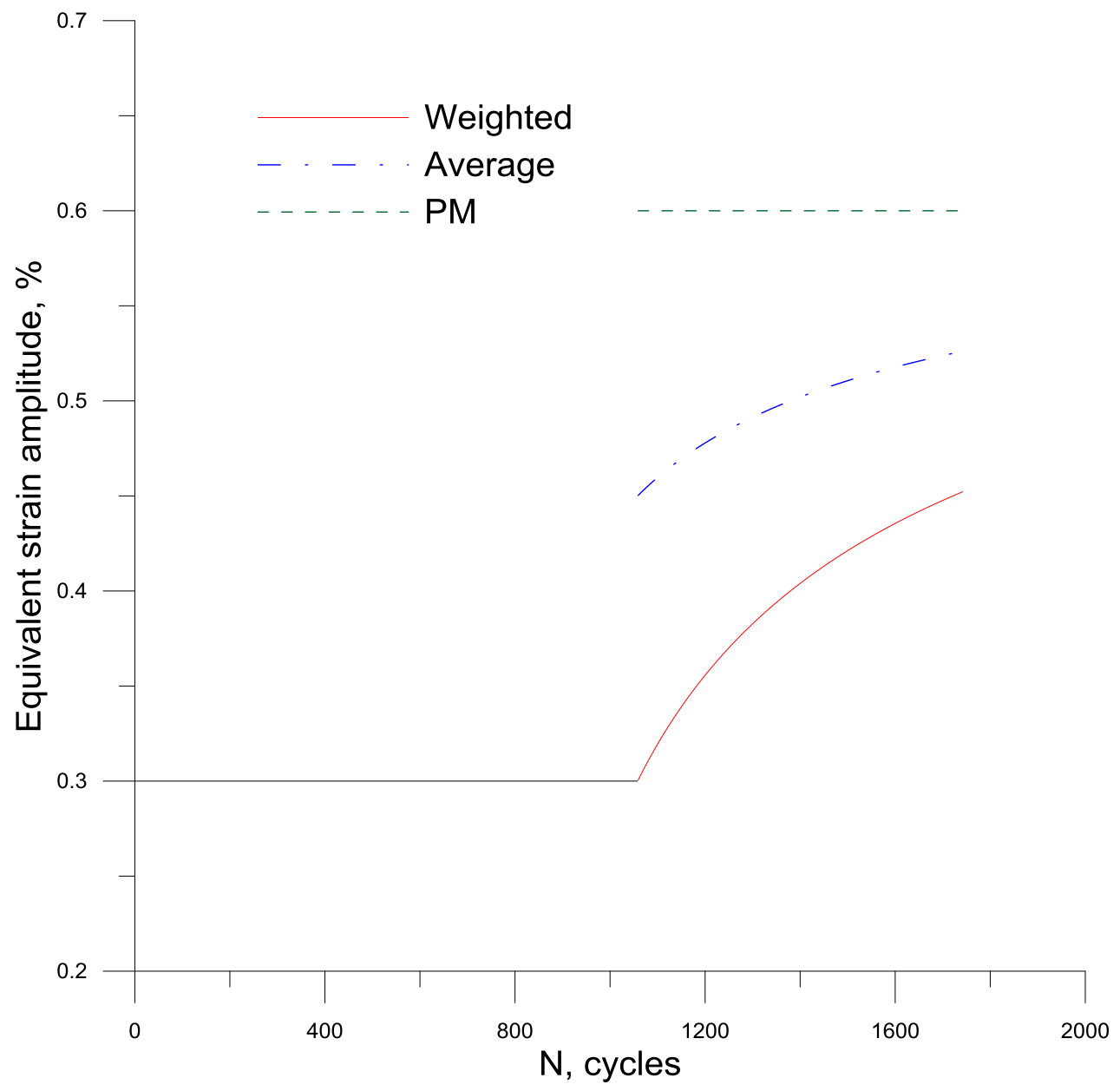

Fig. 2. Equivalent strain amplitude for L-H level of P91 steel in the function of the current number of cycles based on specimen 1_6 


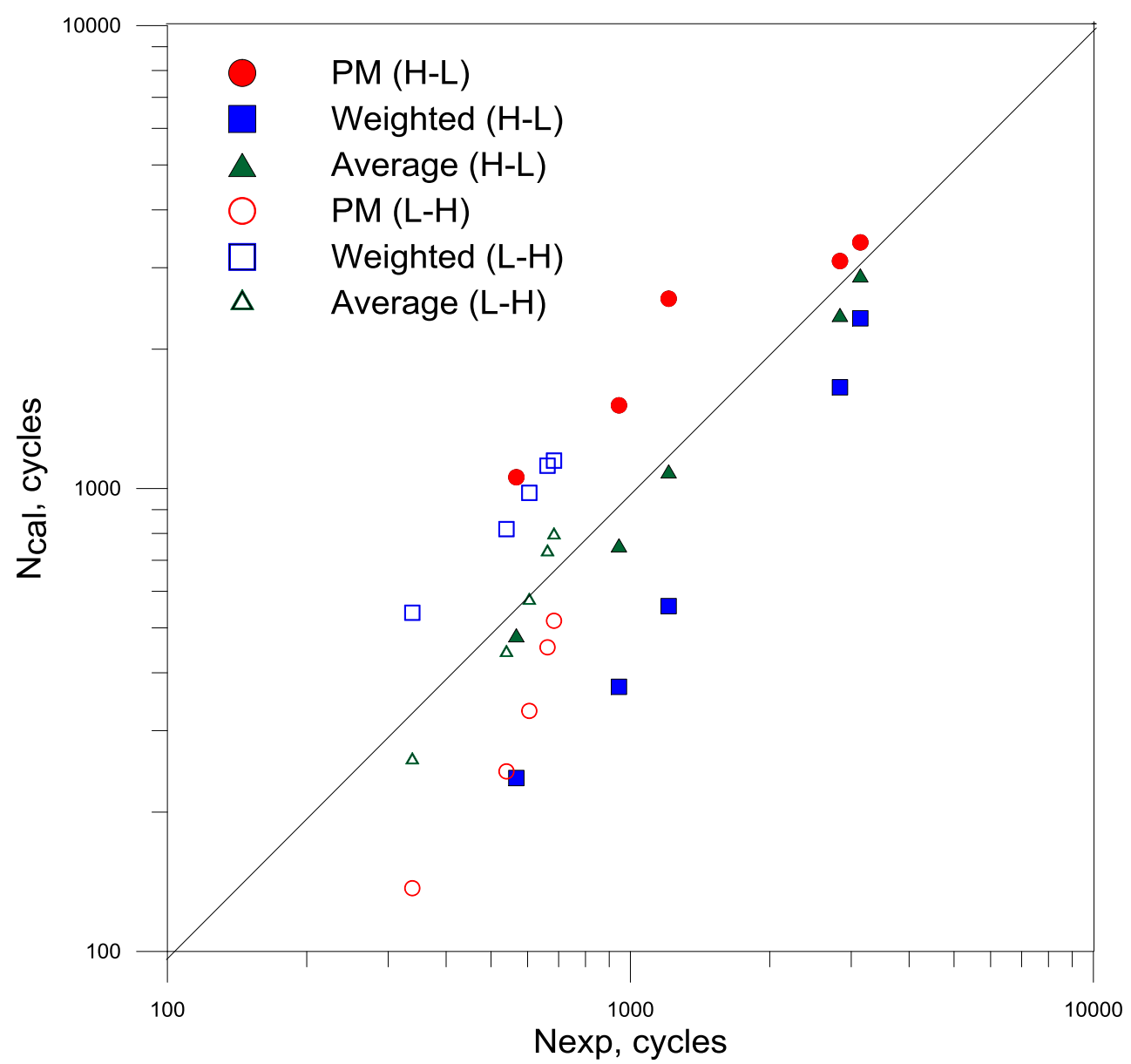

Fig. 3. Comparison of calculated and experimental fatigue lives for second loading block for P91 steel 


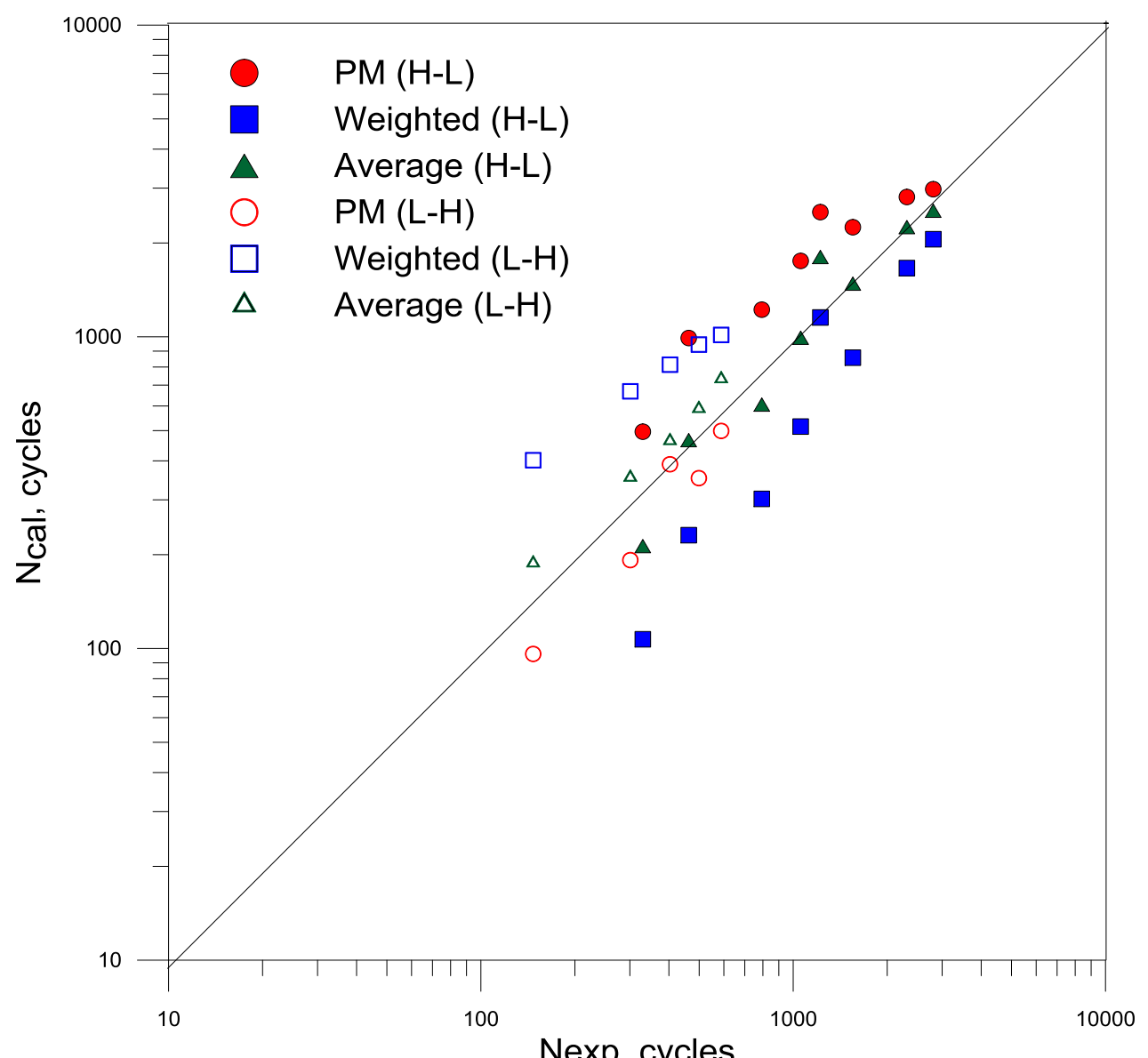

Fig. 4. Comparison of calculated and experimental fatigue lives in the second loading block for P92 steel

\section{Conclusions}

1. For the root mean $n$ of amplitude ( $c$ "), this amplitude approaches asymptotically from the initial value equal to the amplitude from the first type loading block to the amplitude from the second block. If the average value is used, the accumulated amplitude in the second block initiates from the arithmetic mean from the first and second block until it asymptotically approaches along with its aggregation to the one that has been determined for the second block. The pace of this approach occurs much faster than when only the root mean $n$ of amplitude ( $c$ ") is applied.

2. Regardless of the use of the material, we can see that in the case of H-L type loads, the application of the classical Palmgren-Miner hypothesis gives overestimated values of the computed fatigue life. For L-H loads, the result of the fatigue life assessment is underestimated. In the case of applying the root mean $n$ of amplitude for the accumulation of fatigue damage, we have to do with exactly the opposite. Only the use of the arithmetic mean amplitude of the second block and the weighted amplitude in a given cycle gives satisfactory results of the computated fatigue life of the second block. These results assume a waveform that is very close to a straight line describing 
the ideal compliance of the computational life with the experimental one and have the smallest scatter expressed in terms of the mean square.

3. The proposed model of damage accumulation based on the strain history memory in the form of root mean $n$ of amplitude ( $c$ "), seems to be applicable for fatigue damage accumulation for non-stationary histories.

\section{References}

1. A. Palmgren, Die Lebensdauer Von Kugellagern, 68 (1924) 339-341 (1924)

2. M. Miner, Journal of Applied Mechanics, 12 159-164 (1945)

3. C. Bathias, A. Pineau, Eds., Fatigue of materials and structures: fundamentals, ISTE; John Wiley, London: Hoboken, NJ,( 2010)

4. S.V. Serensen, V.P. Kogayev, R.M. Snajdorovic, Maśinostroenie, Izd. 3-e (1975).

5. J. Liu, H. Zenner, Materialwissenschaft und 'werkstofftechnik. 24, 240-249 (1993)

6. S. Marco, W. Starkey, A concept of fatigue damage, 76, 627-659 (1954)

7. J. Szala, Hipotezy sumowania uszkodzeń zmęczeniowych, Akademia TechnicznoRolnicza, Bydgoszcz, (1998)

8. H. Ebbinghaus, Memory: A Contribution to Experimental Psychology, Chapter 1, York University, Toronto, Ontario (1885/1913).

9. E. Bohm, M. Kurek, G. Junak, M. Cieśla, T. Łagoda, Zeszyty Naukowe Politechniki Opolskiej, Mechanika z.103, Nr 351/2014, 37-38 (2014)

10. E. Bohm, M. Kurek, G. Junak, M. Cieśla, T. Łagoda, Procedia Materiale Science, 3, 27 (2014)

11. E. Bohm, M. Kurek, T. Łagoda, K. Łagoda, Solid State Phenomena, 250, 1-9 (2016)

12. E. Böhm, M. Kurek, T. Lagoda, Journal of Testing and Evaluation 48, 4416-4434 (2020)

13. E. Gassner, Betriebsfestigkeit. Konstruktion 6, 97-104 (1954)

14. T. Łagoda, C.M. Sonsino, Mat.-wiss. U. Werkstofftech., 35, 2-61 (2004)

15. G. Junak, M. Cieśla, Archives of Materials Science and Engineering, 48, 19-24 (2011)

16. K. Walat, T. Łagoda, Int. J. Fatigue, 67, 73-77 (2014) 